\title{
OCHO LECCIONES SOBRE ÉTICA Y DERECHO PARA PENSAR LA DEMOCRACIA
}

\author{
Carlos Santiago Nino
}

Siglo XXI Editores, Buenos Aires, 2013 192 páginas. ISBN 978-987-629-329-7

Nicolás E. Alles

De vez en cuando ven la luz iniciativas editoriales que el público de lectores no hace sino agradecer y festejar. Más aún cuando éstas son inesperadas. La publicación de Ocho lecciones sobre ética y derecho para pensar la democracia de Carlos Santiago Nino (1943-1993) pertenecen sin dudas a este grupo selecto de proyectos editoriales. Es un material imprevisto porque el texto que Siglo Veintiuno pone a disposición no fue, originalmente, pensado como un libro, sino que se trata de la transcripción de ocho clases que el filósofo argentino dictó en mil novecientos ochenta y tres en la sede de la Sociedad Argentina de Análisis Filosófico (SADAF). El azar jugó su parte en el hecho de que este material fuera finalmente publicado. Tal como relata Marcelo Alegre en la «Presentación", los casetes con las grabaciones de estos encuentros fueron encontrados casualmente durante una reforma en el edificio de la SADAF.

En términos generales podríamos decir que estas clases de Nino $(y$, por ende, el libro que las contiene) están destinadas a problematizar la relación entre moral y derecho en la reflexión filosófica contemporánea. Nino presenta, con erudición y claridad, los argumentos y problemas que ocupaban a la filosofía moral (primordialmente de corte anglosajón) a principios de los años ochenta del siglo pasado. En un arco que va desde cuestiones de ética analítica (1. Claves de la ética (I): teorías metaéticas y 2. Claves de la ética (II): 
El constructivismo ético) hasta problemas propios de la filosofía del derecho (7. El derecho y la moral y 8. La justificación de la pena) pasando por asuntos de filosofía política (3. La igualdad) o temas referidos a la justificación moral (4. Teorías deontológicas y teleológicas), Nino se encarga de proponer una perspectiva que bien puede complementarse con sus trabajos ya editados. Estos temas y problemas se articulan en la prosa (oral) de Nino para otorgar puntos de vista que sirvan para pensar la realidad argentina de principios de los ochenta, para pensar la realidad de un país que estaba experimentando la transición a la democracia.

Con todo, estas lecciones no constituyen una introducción a las problemáticas enumeradas; por el contrario, el nivel con el que Nino las aborda exige del lector aunque más no sea un mínimo acercamiento previo con las cuestiones tratadas. Recordemos que dichas clases - tal como cuenta Diana Maffia en el «Prólogo»- fueron brindadas en el ámbito de una maestría que se dictó en SADAF. Nino no se detiene a presentar los aspectos centrales de, por ejemplo, Teoría de la Justicia de John Rawls o las líneas principales de la propuesta de Richard Hare; en gran medida parece presuponerlos. Si bien los debates particulares en los que hace foco son los propios de la filosofía moral de principios de la década de los ochenta del siglo pasado, podemos todavía extraer importantes enseñanzas para quienes se dedican a esas áreas de ética o la filosofía del Derecho. La actitud de Nino para encarar las cuestiones que tiene entre manos no es ni conformista ni se reduce a un enfoque simplificador, sino que problematiza los temas que lo ocupan de una manera exhaustiva y precisa. Ejemplos de estos tratamientos son la distinción entre teorías deontológicas y teorías teleológicas, y el debate en torno a la igualdad. Con respecto al primer tema, Nino pone en discusión las implicancias y los alcances de proponer un criterio claro de distinción entre estos tipos de consideración de las teorías morales y termina sospechando de la utilidad de buscar una diferenciación tajante entre estas dos maneras de clasificar a las teorías éticas. Con respecto al problema de la igualdad, no sólo examina las perspectivas en su momento en boga (sobre todo la de Bernard Williams y Thomas Nagel), sino que presenta su propio planteo, que elabora a partir de su comprensión del liberalismo. El principio de inviolabilidad de la persona, el de autonomía y el de la dignidad de la persona son, para Nino, los tres pilares básicos de la concepción liberal de la sociedad. 
A partir de ellos intenta pensar el problema de la igualdad y la posibilidad de conjugarlos para el surgimiento de un nuevo esquema de derechos. En este punto se revela la estrategia del filósofo argentino. Sus clases no se reducen a una exposición; por el contrario, son momentos para discutir su propia postura acerca de los asuntos en cuestión. La lectura del libro dejan una impresión de la que conviene tomar nota: el diálogo con los alumnos era una ocasión para pensar, se trataba de un laboratorio de ideas. Nino pensaba en el diálogo.

Este material se presenta además como una buena ocasión para discutir algunas consideraciones actuales acerca del liberalismo. El libro representa, en este aspecto, un interesante ejemplo de cómo, a partir del liberalismo contemporáneo es posible pensar aspectos de nuestra actualidad. Quizás esto pueda ayudar a poner en cuestión algunos lugares comunes acerca del liberalismo y se pueda ver, además, en el enfoque filosófico propuesto una estrategia fértil para analizar los problemas morales que atraviesan las sociedades contemporáneas.

Por último, las clases no dejan de transmitir un cierto aire de época. Eran los tiempos previos a las elecciones de mil novecientos ochenta y tres y el final de la dictadura, y en la cátedra de Nino se abría el espacio para la reflexión sobre el estado de cosas de un país que, como dice nuestro autor, estaba atravesando «una muy grave crisis moral». Son varias las cosas que nos deja esta publicación. No sólo nos permite acercarnos de una manera distinta a algunos aspectos del pensamiento de Nino, sino que además es un material útil para pensar el vínculo entre liberalismo, moral, derecho y democracia. Tal vez la enseñanza más importante que nos dejen estas transcripciones sea el gesto que Nino lleva acabo. Ahí vemos a un intelectual argentino apelando a un amplio repertorio conceptual que intenta reconstruir debates y planteos para pensar las instancias más delicadas de la sociedad de su tiempo. 